ON THE

\title{
USE OF GUAIACUM IN THE TREATMENT OF CHRONIC GOUTY AFFECTIONS
}

AND ITS

\section{VALUE IN WARDING OFF ACUTE ATTACKS}

$\mathbf{B Y}$

SIR ALFRED B. GARROD, M.D., F.R.S., PHYGICIAN EXTRAORDINARY TO HER MAJESTY THE QUEEN ; CONSULTING PHYSICIAN TO RING'S COLLRGE HOSPITAL.

\section{Received April 30th-Read May 26th, 1896.}

Ar the meeting of the Royal Medical and Chirurgical Society February 8th, 1848, there was read a paper entitled "Observations on Certain Pathological Conditions of the Blood and Urine in Gout, Rheumatism and Bright's Disease," in which I had the privilege of bringing before this Society several very interesting and important points. In the first place I demonstrated the presence of uric acid in the blood, which had never been proved before although often sought for. Secondly, I showed by many analyses that the uric acid was much more abundant in the blood of gouty patients-that in the blood the uric acid existed in the form of urate of sodium; that in health uric acid is scarcely to be found in the 
blood; that in healthy birds, whose urine consists almost entirely of urate of ammonium, uric acid is often altogether absent. These facts were first made known to your Society, and I look upon them as perfectly established by a lengthened experience of forty-eight years. I have mentioned them now as they have reference to matters to which I shall have to allude before I finish this communication.

It can be demonstrated that all truly gouty symptoms are dependent on a morbid condition of the blood, from the presence of a notable quantity of uric acid, or rather urate of sodium, and that deposits of the chalky matter which occur in gouty patients consist chiefly of urate of sodium.

How the uric acid gets into the blood, and where it is formed in the system, we will endeavour to show later on.

I shall first direct your attention to the drug called Guaiacum, which is the resin from the tree called Guaiacum officinale, the wood of which is termed Lignum vitæ, also used in medicine on account of the resin contained in it. It can scarcely be said that guaiacum is much used in medicine at the present time; as a powder it is occasionally added to aperients, such as sulphur, magnesia, \&c., and in the liquid form it is usually prescribed as the ammoniated tincture. In modern books on Materia Medica the medicinal action of guaiacum is but little commented upon. More was said about it by Cullen and other writers over a hundred years ago, who also spoke of other somewhat allied medicines. Many physicians at that time had an impression that when guaiacum was continuously administered, it possessed some power of warding off gouty attacks, but there seemed to be an idea, very strongly held, that the employment of this drug was by no means free from danger. They looked upon the use of these remedies as suppressing but not eradicating the disease.

At Martinico, more than a century ago, a Mr. Emericon proposed the use of guaiacum dissolved in rum; of this 
about a tablespoonful was taken each day, and with very good result, as far as the warding off the attacks was concerned. With regard to the value of this and some other drugs I may quote this statement from Cullen's work: "This fact is certain that from the time of Galen to the present, there are accounts which show the use of certain bitters continued for some time has prevented the return of inflammatory gout."

A rather full discussion on this subject is contained in my work on Gout; but as the readers of this account must be comparatively few, at the risk of a slight repetition I will state my present knowledge of the subject, and how it has been gradually arrived at.

When I first had to treat cases of gout, whether in an hospital or elsewhere, I was accustomed to give salines and alkalines combined with colchicum in moderate doses; under this treatment the patients usually made slow but fairly good progress After the disease became more chronic in character cinchona was often added to the mixture, and as a ruib the improvement continued, and the patient slowly regained his healthy condition. After a time I was induced to try guaiacum, usually as the ammoniated tincture, and I soon became aware of what was gained by this addition; the progress towards recovery was much hastened and the cure in all respects more complete. Perseverance in this plan made the treatment of gouty attacks infinitely more satisfactory, aud many patients became so convinced of the action of the Guaiacum that they would not allow themselves to be without it, having it always within reach. I feel sure that I am within the mark when I say that this new method of treatment shortened the duration of the attack to at least one half, allowing the doses of the colchicum to be considerably lessened. It is sometimes desirable to add other remedies to the guaiacum, as iodide of potassium, citrate of lithium, and different salines.

After a short time, meeting with patients who were troubled with attacks of gout at fairly regular intervals, 
I was induced to make a trial of guaiacum as a prophylactic.

The first case was a man about sixty-six years of age; for many years he had been accustomed twice a year to have attacks of gout of two or three weeks' duration. He was recommended to continue the diet to which he had been accustomed before he began the treatment, and he was ordered to take early each morning a powder containing twelve grains of guaiacum, the same amount of cinchona bark, a little iodide of potassium and citrate of lithium, with a trace of the corm of colchicum. At first I thought it a necessity to give some colchicum, but the quantity was so insignificant that it could have produced but little or no effect.

For two years and three quarters this patient continued the daily use of the powder, and during the whole of that time he was free from gouty attacks, and never, I believe, had any more during his life. This case was much against Cullen's views, who thought that patients always suffered when their gouty attacks ceased, for his health remained remarkably good after he had ceased to take the powder. When he had passed his eightieth birthday he remarried, and lived till eighty-seven years of age; his death then being hastened by his falling down a flight of stone steps on leaving a dinner party.

Long before this first patient had completed his course, many others were put upon the same treatment. Two of these were men who in the course of their business had to go to China and Japan, and were eighteen months or two years away from England. It had been their lot to be laid up certainly once or twice with attacks of gout in a foreign land. Under this treatment, everything else remaining the same, they went out and returned home again, having been free from any illness during the long journey.

Since the time the above cases were treated so successfully, I have had, I should think, nearly a hundred other patients who have more or less rigorously followed this 
treatment, and at the present time many are under the influence of guaiacum. I purposely do not give it alone, because I think much advantage may be obtained from the addition of other remedies. For example, I almost always add citrate of lithium: as I feel sure the beneficial action of the guaiacum is much improved by it, and not infrequently I give the guaiacum as a cachet, followed by a very pleasant draught of the effervescing citrate. Neither can be regarded as medicines, seeing they may be taken indefinitely in the same way as food.

Before concluding this account of the action of guaiacum, I may here relate a circumstance which has occurred to me many times. Patients to whom I have prescribed guaiacum after taking it for a few days have come again complaining of the effect which the guaiacum has had on the urine; that whereas before taking it the urine was very clear and healthy-looking, since its administration it had become thick and looking very unhealthy; when, however, these same patients were asked about their health, they all acknowledged they were feeling better, and in all respects going on satisfactorily. Without at present endeavouring to explain the action of guaiacum upon the urinary secretion, it is quite certain that it frequently causes the copious elimination of uric acid in the form of urates, which probably is in close relation to its efficacy in gouty cases.

I often give the guaiacate of lithium in the form of pills. It is a preparation I introduced at least twenty years ago, and which seems to act very efficiently.

Cullen and others, who recognised the effect of guaiacum in arresting gouty attacks, considered that the same power resided, at any rate in some degree, in other medicinal substances, and practical experience has taught me that Serpentary, the rhizome and rootlets of Aristolochia serpentaria, is one of these substances. When from any cause a patient is unable to take guaiacum for any length of time, a circumstance which seldom occurs, then serpentary seems to be able to take its place; and 
I have several patients, usually elderly men, who have found great benefit from this medicine in their gouty attacks, and several who have been most unwilling to be ever without it, but as yet I can give no such evidence of its prophylactic powers as I can in the case of guaiacum.

I give the serpentary in the form of extract as well as in that of a tincture.

Before concluding my remarks on the action of drugs on gouty conditions of the system, it is of much importance that colchicum should be alluded to.

- Every one who has had any experience in the treatment of gouty cases must be aware that this drug possesses very great power of controlling the inflammatory action which occurs in the articular structures, and that in the treatment of attacks of gout it is perhaps unequalled, but as a prophylactic its value is more doubtful, and few would like to give it in doses sufficiently large to keep the disease at bay for any very lengthened period. I believe that colchicum possesses the greatest power of checking gouty inflammation when present, but little or none in preventing its recurrence.

There is also a feeling in the minds of many of the public, also of some of the profession, that colchicum although curative of existing gouty inflammation, possesses also the power of causing its rapid recurrence, and that in cases of gout treated by efficient doses of this drug there is a tendency to relapse. I must confess that in my own experience I have never noticed this, except in cases treated by quack medicines containing large quantities of colchicum, when the relapses have been frequent and very unyielding.

I think we may safely say that although colchicum is a most potent and valuable remedy in gouty inflammation, it is not one that can be given for a very lengthened period of time in large doses, and that it is far inferior to guaiacum as a prophylactic.

In order to attempt to give an explanation of the action of guaiacum in relieving and keeping off attacks 
of gout, it will be necessary to state my views of the formation and secretion of uric acid in the animal body. Some fifty or sixty years ago it was considered that uric acid was produced by the kidney itself; it had been songht for in the blood, but without success; when, however, this principle was found in the circulating tluid, the ideas of its origin in the body were changed, and up to the present time the view held by physiologists is as follows :-in the metabolism of the nitrogenised tissues of the body, urate of ammonium is first formed, which in some animals is at once thrown out by the kidney; for instance, this is the case in all birds and in most reptiles; in other animals a further change takes placeurea is formed from the urate of ammonium and in that condition eliminated by the kidneys.

When carefully examined the objections to this hypothesis are very numerous and to my mind insuperable. They will be found detailed in a paper in the Proceedings of the Royal Society, vol. Iviii. In the same communication I stated my own views derived from a thorough investigation of the facts. The opinions I hold on the subject amount to this :

1. That in the metabolism of the nitrogenised tissues of the body urea is first formed. I found urea in the blood of birds whose urine usually contains none of this principle, as well as in the blood of mammals whose urine contains it in abundance.

2. That uric acid in the form of urate of ammonium is formed in the kidneys themselves from urea (not urea from urate of ammonium) and is thrown out in that form.

3. When uric acid (as urate of sodium) is found in the blood I consider that this arises from the absorption from the kidney structure, where in man it is apt to be retained for a time; but in the blood of the healthy bird, such as the pigeon, whose excretion is entirely urate of ammonium, no uric acid can be detected; this was stated in my communication to this Society in February, 1848.

Holding this view of the origin of uric acid, we can 
explain the action of guaiacum in this way. We must assume that guaiacum acts as a stimulant on the kidney itself, and causes that organ to throw off any urate of ammonium remaining in its structure, thereby preventing absorption into the blood. If this is the case, it can be easily understood why its continued use prevents any accumulation from taking place, and prevents the blood from being contaminated by its absorption. If this view is correct it is worth while to investigate the action of guaiacum in cases where calculi are being formed.

With regard to the action of guaiacum, it may be confidently asserted that it has no chemical action on uric acid or urate of ammonium, so no clue to its action can be obtained from its chemical action; it has no solvent power of any kind, its action appears to be a stimulant on the capillary blood vessels, not on the heart itself, and it is on the mucous membranes that its action is most evident, especially on the genito-urinary organs.

In conclusion, I hope I have been successful in establishing the following points as to the action of guaiacum:-

1. Guaiacum is an absolutely innocuous substance, and may be taken for an indefinite period of time; it may be looked upon rather as a condiment than as a drug ; it is as innocent as ginger or any other spice.

2. Guaiacum possesses a considerable power, less than colchicum, in directly relieving patients suffering from gouty inflammation of any part; it may be given whenever the patient is not very feverish.

3. Guaiacum taken in the intervals of gouty attacks has a very considerable power of averting their recurrence, even over a lengthened period; it is, in fact, a very powerful prophylactic.

4. Guaiacum from long-continued use does not lose its prophylactic power.

5. Guaiacum, although it can be taken by most individuals, is apt in a few cases to cause irritation of the bowel, so as to prevent its administration as a remedy in gout. In such cases serpentary may be often substi- 
tuted with advantage, although it is as yet doubtful whether it equals guaiacum in its prophylactic power.

If the statements contained in this communication have the effect of inducing my medical brethren to direct their attention to the value of guaiacum in the treatment and prevention of gout, I feel I shall have conferred some benefit on the profession, and through them on the public at large.

(For report of the discussion on this paper, see 'Proceedings of the Royal Medical and Chirurgical Society,' Third Series, vol. vi, p. 230.) 